\title{
Intermittent surgeon career evaluation is needed from beginning to end
}

\section{Christopher M. Feindel, B Eng, MD, MSc, FRCS(C)}

Most of us who plan to attend the 2022 American Association for Thoracic Surgery Annual Meeting in person in Boston will board an airplane. Few of us will question the pilot's ability to get us safely there. Many surgeons are familiar with the parallels between what we do in the operating room and what pilots do in the cockpit and surgical teams have adopted several protocols developed by the airline industry. ${ }^{1-3}$ Preoperative checklists, time-outs, as well as regular debriefing sessions are now considered standard practices. These safety checks notwithstanding, the single most important factor for successful surgery is the surgeon him- or herself. How comfortable would we be if we learned that the pilots flying us to Boston were reevaluated based on successfully passing some written tests or simply providing evidence that several conference sessions had been attended without any reevaluation of actual flying skills?

In Canada, a basic pilot's license allows an individual to fly a single-engine aircraft during daytime and fair-weather conditions. However, to advance to flying commercial airlines with passengers aboard, pilots must accumulate several thousand additional hours of simulation and actual flight experience. ${ }^{4,5}$ In some respects, a fully certified commercial pilot is not dissimilar to a fully certified surgeon. Even after being certified to fly commercial flights, a pilot must undergo regular reevaluation both in a simulator and while operating an actual aircraft under the scrutiny of a senior experienced pilot.

Many airline standards that exist today came about in response to the worst accident in airline history, which occurred in 1977 at Tenerife Airport in the Canary Islands. A KLM 747 taking off struck a Pan Am 747 that was taxiing down the same runway, killing 583 people. ${ }^{6}$ Extensive analysis of the black box recordings from that and other airline accidents concluded that accidents frequently occur

From the Peter Munk Cardiac Centre, University Health Network, University of Toronto, Toronto, Ontario, Canada.

Presented at the 101st Annual Meeting of The American Association for Thoracic Surgery, Cardiothoracic Ethics Forum: Measuring surgical competence: why, when, how, and what to do about it. May 2, 2021.

The editorial review of this paper was handled by Associate Editor Francis D. Pagani, MD.

Received for publication Sept 10, 2021; revisions received Oct 21, 2021; accepted for publication Nov 2, 2021; available ahead of print Nov 13, 2021.

Address for reprints: Christopher M. Feindel, B Eng, MD, MSc, FRCS(C), Peter Munk Cardiac Centre, University Health Network, Toronto General Hospital and the University of Toronto, 200 Elizabeth St, Room 4NU-480, Toronto, Ontario M5G 2C4, Canada (E-mail: Chris.feindel@uhn.ca).

J Thorac Cardiovasc Surg 2022;164:1030-2

$0022-5223 / \$ 36.00$

Copyright (c) 2021 by The American Association for Thoracic Surgery

https://doi.org/10.1016/j.jtcvs.2021.11.020 
skills we all agree are central to successful and safe surgery. Typically, it is left to a division chief to confirm that a surgeon maintains his or her clinical competency and it is usually only in extreme cases of obvious deficiencies in competencies that a surgeon might have his or her privileges restricted or revoked. In the province of Ontario, age alone cannot be used to prevent a physician from practicing, although all physicians older than age 70 years are subjected to review. However, this review consists only of a chart audit.

As self-governing professionals, we should review our current processes for regular, ongoing evaluation of performance throughout a surgeon's career. I propose that such a process should consider the following approaches:

- A review of a surgeon's operative mortality, morbidity, and resource utilization.

- Peer review of outcomes. In our center, we share surgeonspecific outcomes, internally in a deanonymized fashion, based on the Society for Thoracic Surgeons database. This takes advantage of the strong effect that peer review has in improving outcomes. We have also augmented our mortality and morbidity reviews to follow the Australia and New Zealand Audit of Surgical Mortality, where surgeon mortalities are reviewed by internal peers who provide anonymous feedback with a focus on identifying whether or not a death was preventable. ${ }^{9}$

- An internal $360^{\circ}$ review by peer surgeons and possibly nurses, anesthesiologists, and perfusionists.

Surgery is very much a team activity where members include anesthesiologists, nurses, perfusionists, fellows, and resident physicians, all of whom have numerous opportunities to observe individual surgeons in a variety of circumstances. In fact, hospital staff, including surgeons, will frequently seek out opinions from these individuals if they require a surgical procedure for themselves or for a family member. In our center, as in many other centers, the COVID-19 pandemic provided opportunities for staff surgeons to work with each other more than ever before, allowing for direct observations of a peer's performance (Figure 1). Why not utilize this opportunity to develop an anonymous $360^{\circ}$ review process? Not only would such a team review provide valuable feedback to each surgeon, but it also would likely detect any early decline in a surgeon's performance, which may help mitigate serious consequences that might affect patient safety. To be successful, an entire surgical team must support this level of peer review and be willing to help each other in a constructive, nonpunitive manner. It may not be suitable for all programs or for all situations, and involuntarily imposing such an evaluation process runs the risk of it being used inappropriately with potentially negative consequences. Ideally, review activities should be overseen by a quality officer

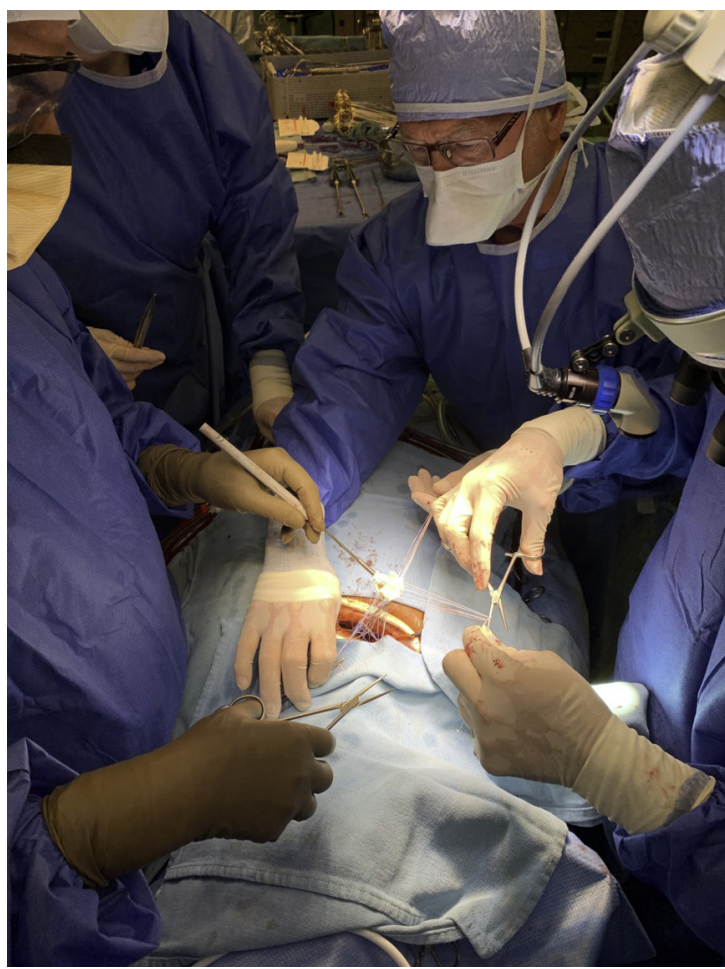

FIGURE 1. A senior surgeon (C.M.F.) assisting and observing an attending surgeon colleague in the performance of a minimally invasive aortic valve operation.

who is a respected peer, preferably at arm's length from a division or department chief.

In Canada, we have not adopted public reporting of individual surgeon mortality rates as a means to evaluate surgeons in part because these metrics can be fraught with potential problems and can lead to unintended consequences. ${ }^{10-12}$ Looking ahead, and again following the example of the airline industry, there is increasing recognition of the power of visual feedback (eg, simulation) and how this might be combined with artificial intelligence to provide useful, objective analysis of a surgical team's performance. ${ }^{13-16}$

We owe it to ourselves and to our patients to ensure that there are robust, well-defined processes in place for ongoing internal evaluation of surgeon performance throughout our careers. Applied appropriately, these will augment public trust in our profession.

\section{Conflict of Interest Statement}

The author reported no conflicts of interest.

The Journal policy requires editors and reviewers to disclose conflicts of interest and to decline handling or reviewing manuscripts for which they may have a conflict of interest. The editors and reviewers of this article have no conflicts of interest. 


\section{References}

1. Wadhera RK, Parker SH, Burkhart HM, Greason KL, Neal JR, Levenick KM. Is the 'sterile cockpit' concept applicable to cardiovascular surgery critical intervals or critical events? The impact of protocol-driven communication during cardiopulmonary bypass. J Thorac Cardiovasc Surg. 2010;139:312-9.

2. Kapur N, Parand A, Soukup T, Reader T, Sevdalis N. Aviation and healthcare: a comparative review with implications for patient safety. JRSM Open. 2015;7. 2054270415616548 .

3. Sexton B, Thomas EJ, Helmreich RL. Error, stress, and teamwork in medicine and aviation: cross sectional surveys. BMJ. 2000;320:745-9.

4. Canadian Aviation Regulations. Standard 421 - Flight crew permits, licenses and ratings; 2006. Accessed May 10, 2021. https://tc.canada.ca/en/corporateservices/acts-regulations/list-regulations/canadian-aviation-regulations-sor-96433/standards/standard-421-flight-crew-permits-licences-ratings-canadian-avia tion-regulations-cars

5. Air Canada Pilots Association/Association des pilotes d'Air Canada. Pilot Training. Accessed May 10, 2021. https://acpa.ca/pilot-life/pilot-training.aspx

6. Ziomek J, Hopkins C. Collison on Tenerife: The How and Why of the World's Worst Aviation Disaster. Post Hill Press; 2018.

7. Helmreich RL, Foushee HC. Why crew resource management? Empirical and theoretical bases of human factors training in aviation. In: Weiner E, Kanki B, Helmreich R, eds. Cockpit Resource Management. Academic Press; 1993: $3-45$.
8. The Royal College of Physicians and Surgeons of Canada. The Maintenance of Certification (MOC) program. Accessed May 10, 2021. https://www.royalco llege.ca/rcsite/cpd/maintenance-of-certification-program-e

9. Royal Australasia College of Surgeons. Surgical mortality audits. Accessed May 10, 2021. https://www.surgeons.org/en/research-audit/surgical-mortality-audits

10. Moffatt-Bruce SD, Nguyen MC, Fann JI, Stephen Westaby S. Our new reality of public reporting: shame rather than blame? Ann Thorac Surg. 2016;101:1255-61.

11. Guru V, Naylor D, Fremes S, Teoh K, Tu J. Publicly reported provider outcomes: the concerns of cardiac surgeons in a single-payer system. Can J Cardiol. 2009; 25:33-8.

12. Radford PD, Derbyshire LF, Shalhoub J, Fitzgerald JEF. Publication of surgeon specific outcome data: a review of implementation, controversies and the potential impact on surgical training. Intl J Surg. 2015;13:e211-6.

13. The Surgical Intelligence Platform. Seize your defining moments. Accessed May 11, 2021. https://theator.io

14. Likosky D, Yule SJ, Mathis MR, Dias RD, Corso JJ, Zhang M, et al. Novel assessments of technical and nontechnical cardiac surgery quality: protocol for a mixed methods study. JMIR Res Protoc. 2021;10:e22536.

15. Feins R, Burkhart HM, Conte JV, Coore DN, Fann JI, Hicks GL, et al. Simulation-based training in cardiac surgery. Ann Thorac Surg. 2017;103:312-21.

16. Ribeiro IB, Ngu JM, Lam BK, Edwards A. Simulation-based skill trainees in cardiac surgery: a systematic review. Ann Thorac Surg. 2018;105:972-82.

Key Words: surgeon performance, surgeon evaluation 